\title{
28 Research Square

\section{Management of COVID-19 in a nursing home: the role of a mobile multidisciplinary medicine team.}

Pierre Poupin ( $\square$ poupinpierre@yahoo.fr)

Centre Hospitalier Régional Universitaire de Tours

Diama N'Diaye

Centre Hospitalier Régional Universitaire de Tours

\section{François Chaumier}

Centre Hospitalier Régional Universitaire de Tours

Adrien Lemaignen

Centre Hospitalier Régional Universitaire de Tours

\section{Louis Bernard}

Centre Hospitalier Régional Universitaire de Tours

\section{Bertrand Fougère}

Centre Hospitalier Régional Universitaire de Tours

\section{Short Report}

Keywords: viral respiratory diseases, outbreaks, nursing homes, multidisciplinary collaboration

Posted Date: September 11th, 2020

DOl: https://doi.org/10.21203/rs.3.rs-73220/v1

License: (c) (i) This work is licensed under a Creative Commons Attribution 4.0 International License.

Read Full License 


\section{Abstract}

Background: Long-term residential care facilities and nursing homes are known to be particularly vulnerable to viral respiratory diseases and have expressed the need for collaboration to help manage outbreaks when they occur.

Method: In April 2020, Tours University Hospital created a mobile multidisciplinary medicine team to help local nursing homes deal with outbreaks of coronavirus disease 2019 (COVID-19). The team included a geriatrician, infectious diseases experts, and palliative care specialists.

Results: Here, we provide initial feedback on the mobile support team's first intervention. The nursing home staff's main requests were collaborative working, consensus decision-making, and the dissemination of information on disease management.

Conclusion: Three lessons emerged from this collaboration: (i) break the nursing home's isolation, (ii) limit transmission through the use of appropriate hygiene measures, broad screening, and the isolation of sick residents and sick employees, and (iii) provide sufficient human resources.

\section{Background}

In December 2019, a previously known type of pneumonia associated with severe acute respiratory syndrome emerged in the city of Wuhan (China) ${ }^{1}$. In January 2020, the pathogen was isolated and described as severe acute respiratory syndrome coronavirus 2 (SARS-CoV-2) ${ }^{1}$. The corresponding disease (coronavirus disease 2019, COVID-19) spread rapidly around the world, prompting the World Health Organization to declare a global pandemic on March $11^{\text {th }}, 2020^{2}$. In Europe and for example in France, a total of 142,852 confirmed cases had been reported on May $28^{\text {th }}, 2020^{3}$. Of these, 33,646 concerned nursing home residents (leading to 13,806 death $^{4}$ ) and 16,215 concerned nursing home staff.

Long-term residential care facilities and nursing homes are known to be particularly vulnerable to viral respiratory diseases (e.g. influenza) ${ }^{5,6}$. Due to frailty and the presence of comorbidities, older adults are more likely to experience severe and/or complicated forms of COVID-19, with a higher mortality rate ${ }^{7}$.

On March $12^{\text {th }}, 2020$, the French government prohibited visits to nursing homes by family members. In fact, many establishments had anticipated this decision and had stopped visits a week previously. Access to nursing homes was limited to employees only. Despite these measures, the rapid spread of SARS-CoV-2 resulted in many cases of COVID-19 among nursing home residents by the end of March.

Faced with this unprecedented health crisis, Tours University Hospital (Tours, France) created a mobile multidisciplinary medicine team (MTMT) to help affected nursing homes deal with COVID-19 in a coordinated manner. The concept of a mobile geriatric team has emerged in France and other countries over the last decade, in response to the constant requirement for cost-effective treatment procedures that optimize resources. To the best of our knowledge, MTMTs have rarely been used to deal with COVID-19 
outbreaks among older adults in our country. The objective of the present report was to share our experience of this novel collaboration between nursing homes and a university hospital's geriatric medicine department.

\section{The collaboration between the nursing home and the MTGMT:}

The MTMT included a geriatrician, two infectious diseases experts, and two palliative care specialists (a nurse and a physician). In April 2020, the MTMT's first intervention took place in a 100-resident nursing home in the city of Tours. The nursing home's three floors were each divided into 2 units, and there were 60 care staff. The team members first met with the nursing home's coordinating physician, head nurse, and director. The nursing home's COVID-19 outbreak had started about 2 weeks previously; the first confirmed cases among the residents were recorded on March $26^{\text {th }}$. This disease spread rapidly to all the units, with a total of 11 confirmed cases among the residents and 6 among the nursing staff. Around half of the nursing staff had developed symptoms of COVID-19 but a shortage of tests prevented confirmation of these suspected cases. Four of the 11 SARS-CoV-2-positive residents had died at that point.

It appeared that the nursing home's first case of COVID-19 was a member of staff who subsequently tested positive for SARS-CoV-2. This member of staff had come at work with respiratory symptoms, had not used personal protective equipment (PPE), and had been in close contact with the first of the residents to fall ill. Furthermore, the lack of knowledge about the risk of SARS-CoV-2 transmission by asymptomatic carriers and sometimes contradictory guidance about PPE use had resulted in confusion and a lack of clear recommendations for the care staff.

Three key issues emerged from the MTMT's initial assessment: (i) nursing home staff must know how to recognize the signs and symptoms of COVID-19, be aware of how the disease is transmitted, and use PPE appropriately; (ii) the criteria for transferring confirmed cases of COVID-19 to hospital were not clear; and (iii) there was a need for information about patient management and a specific organizational structure for dealing with the outbreak of COVID-19.

The MTMT's infectious diseases experts first outlined the procedures for outbreak management. The nursing home staff were given detailed information on the virus's mode of transmission and the main strategies for preventing it from spreading: cohorting staff (to limit mixing and opportunities for transmission), limiting staff meetings or seminars, applying social distancing during staff meal breaks, and wearing a face masks at all times. To preserve supplies, the use of PPE was optimized (2 disposable surgical face masks per day and per person).

With regard to specific management, the palliative care physician and the geriatrician suggested fundamental changes in the care environment and transfer of confirmed cases of COVID-19. This included asking whether the residents had given advanced directives, and determining whether the nursing home was able to meet a resident's medical needs. It was decided that hospital admission would be recommended for patients with few comorbidities or a low level of dependence, or when other 
diagnoses had to be ruled out. In fact, most cases appeared to be too advanced to benefit from hospitalization. In other cases, the resident had clearly expressed the wish to stay in a familiar environment.

With regard to treatment, the MTMT considered the benefits of antibiotics in certain situations and emphasized the importance of preventing dehydration, undernutrition, and loss of functional autonomy. The team reviewed the nursing home's ability to provide oxygen therapy, palliative care, and end-of-life care. These procedures increased the burden of care and prompted the creation of COVID-19-only units.

\section{Results And Perspectives}

Following our intervention, three residents with few comorbidities were immediately hospitalized. In local hospitals and clinics, scheduled surgical interventions were suspended and only emergencies operations were carried out; this reduction in the level of activity freed up staff for temporary redeployment to nursing homes. Home hospital units also provided staff reinforcements for patients requiring a high level of care. The nursing home's stocks of PPEs, medications and medical equipment were considered to be sufficient. At the request of the nursing home's coordinating physician and director, all the residents and all the staff members were finally screened for SARS-CoV-2 in nasopharyngeal swabs, using a reverse transcriptase polymerase chain reaction (RT-PCR) assay; this detected a number of asymptomatic carriers among the residents and employees. The residents who tested positive were isolated in a dedicated unit for two weeks or until they tested negative. The staff members who tested positive isolated at home for two weeks. At the height of the crisis, approximatively a third of the residents were confirmed cases; the outbreak stabilized thereafter.

Collaboration between healthcare professionals appears to be crucial for developing guidance on managing COVID-19: it combines the nursing home staff's knowledge of their residents and expertise in allocating resources within their own facilities, the geriatrician's approach to caring for frail, older adults, the palliative care specialist's expertise in end-of-life care, and the infectious disease specialist's expertise on the management of infections.

\section{Conclusions And Implications}

Nursing homes are extremely vulnerable to contagious viral respiratory diseases (e.g. COVID-19). Outbreaks can be dramatic and preventing the virus from spreading is a priority ${ }^{8}$.

The COVID-19 pandemic highlights the need for collaboration between nursing homes and other health care establishments ${ }^{9}$. The lessons that emerged from this initial collaboration can be summarized as followed:

1. Breaking the nursing home's isolation enables consensus decision-making, the dissemination of information, and multidisciplinary collaboration. 
2. Transmission of the virus must be limited by adopting appropriate hygiene measures (e.g. protective face masks), screening all nursing home residents and employees with an RT-PCR assay, and isolating all confirmed cases

3. Sufficient human resources must be deployed quickly when faced with such exceptional circumstances.

We hope that this feedback will help the authorities to provide precise, specific guidelines on all aspects of managing COVID-19 outbreaks in nursing homes.

\section{Declarations}

Acknowledgements: the authors thank the staff of the nursing home in which the intervention took place for their incredible dedication to the residents' care.

Funding sources: This research did not receive any funding from agencies in the public, commercial, or not-for-profit sectors.

Conflicts of interest: the authors declare no conflicts of interest.

\section{References}

1 - Zhu N, Zhang D, Wang W, et al. A novel coronavirus from patients with pneumonia in China, 2019. N Engl J Med 2020; 382: 727-733.

2 - World Health Organization. Rolling updates on coronavirus disease (COVID-19). 2020

(https://www.who.int/emergencies/diseases/novel-coronavirus-2019/events-as-they-happen. opens in new tab). (30 may 2020, last accessed)

3 - World Health Organization. Coronavirus disease 2019 (COVID-19): situation report - 111. May 28, 2020. (https://www.who.int/docs/default-source/coronaviruse/situation-reports/20200528-covid-19sitrep-129.pdf?sfvrsn=5b154880_2). Accessed May 30, 2020.

4 - French Public Health Agency. COVID19. Weekly epidemiological record, 29 may 2020. (French). (https://www.santepubliquefrance.fr/maladies-et-traumatismes/maladies-et-infectionsrespiratoires/infection-a-coronavirus/documents/bulletin-national/covid-19-point-epidemiologique-du-29mai-2020). Accessed May 30, 2020.

5 - Hand J, Rose EB, Salinas A, et al. Severe respiratory illness outbreak associated with human coronavirus NL63 in a long-term care facility. Emerg Infect Dis 2018; 24:1964-6. 
6 - McMichael TM, Currie DW, Clark S, et al. Epidemiology of Covid-19 in a Long- Term Care Facility in King County, Washington. N Engl J Med. 2020;382:2005-2011.

7 - Wang L, He W, Yu X. Coronavirus disease 2019 in elderly patients: characteristics and prognostic factors based on 4-week follow-up. J Infect. 2020 Jun;80(6):639-345.

8 - Tan LF, Seetharaman S. Preventing the Spread of COVID-19 to Nursing Homes: Experience from a Singapore Geriatric Centre. J Am Geriatr Soc. 2020;68(5):942.

9 - Stall NM, Farquharson C, Fan-Lun C et al. A Hospital Partnership with a Nursing Home Experiencing a COVID-19 Outbreak: Description of a Multi-Phase Emergency Response in Toronto, Canada. J Am Geriatr Soc. $2020,10.1111 /$ jgs.16625. Online ahead of print. 